\title{
Dominantly inherited Alzheimer's disease: cerebral glucose metabolism
}

\author{
R J POLINSKY,* H NOBLE, $\dagger$ G DI CHIRO, $\ddagger$ L E NEE, ${ }^{*}$ R G FELDMAN, \\ R T BROWN*
}

From the Clinical Neuropharmacology Section, ${ }^{*}$ and Neuroimaging Section, $\ddagger$ N.I.N.C.D.S., Bethesda, MD; the Department of Radiology, $\uparrow$ University of Florida, Gainsville, Fl; and the Department of Neurology, $\S$ Boston University School of Medicine, Boston, MA, USA

SUMMARY Cerebral glucose metabolic rate (CMRGlu), measured by positron emission tomography, was bilaterally and symmetrically reduced in two patients with autosomal dominant Alzheimer's disease. Supramarginal gyri and temporal lobes were most severely affected. An isolated reduction of CMRGlu in the left supramarginal gyrus was observed in one asymptomatic at-risk subject.

Diagnostic accuracy is a major limitation to clinical research in Alzheimer's disease. As many as $50 \%$ of clinically diagnosed Alzheimer's disease cases have a different aetiology for dementia found at postmortem examination. ${ }^{1}$ We have previously reported two extensive pedigrees with autosomal dominant inheritance of Alzheimer's disease which has been verified by multiple histopathological examinations. $^{2-4}$ Early age of onset and uniform disease expression within these families facilitate diagnosis. Diagnostic accuracy can be inferred within these pedigrees through post-mortem examination of other closely related, affected family members. First-degree relatives of affected members in these families constitute the highest risk group for longitudinal investigation of Alzheimer's disease. There do not appear to be any significant clinical or neuropathological differences between sporadic and familial Alzheimer's disease.

Positron emission tomography (PET) coupled with administration of ${ }^{18} \mathrm{~F}$-2-deoxyglucose (FDG) allows assessment of brain metabolic activity. ${ }^{56}$ Both global $^{7-12}$ and regional ${ }^{13-19}$ reductions as well as lateral asymmetries ${ }^{2021}$ in the glucose metabolic rate of patients with presumed Alzheimer's disease have been reported; these changes correlate with cognitive deficits ${ }^{152-24}$ and dementia severity. ${ }^{1825}$ In order

Address for reprint requests: Ronald J Polinsky, M.D., National Institutes of Health, Building 10, Room 5N236, 9000 Rockville Pike, Bethesda, Maryland 20892, USA.

Received 17 June 1986 and in revised form 8 August 1986. Accepted 13 September 1986 to surmount some of the diagnostic and technical limitations of investigating brain glucose metabolism in Alzheimer's disease, we have employed a high resolution scanner using FDG as a tracer to study two affected members and two of their asymptomatic atrisk family members, all of whom are first-degree relatives of cases of Alzheimer's disease proven atô necropsy.

\section{Methods}

Subjects The Alzheimer's disease cases and their at-risk relatives were admitted to the Clinical Center, National Institutes of Health. Four normal individuals (three men, one woman) ranging in age from 41 to 50 were selected for the control group. The mean $( \pm$ SEM) age of the controls was $44( \pm 2)$ years, a value midway between the average age of $\mathbf{4 8}$ for the patients and that of $\mathbf{4 0}$ for the at-risk subjects. All subjects gave informed consent in accordance with NIH guidelines. Patients and at-risk subjects underwent a detailed medical and neurological examination. Routine blood tests, thyroid function tests, serum vitamin B12 and folate levels, urinalysis, EKG, and CSF examination were normal. CT and MRI scan of the head, EEG, and neuropsychological evaluation were performed including a Blessed Dementia Scale rating. ${ }^{26}$ None of the subjects were taking medication prior to this admission. The at-risk subjects had normal neurological examinations. A section of the main pedigree for each family illustrates the relationship of the subjects to other affected and at-risk members (fig 1). Neuropathological findings in affected family members have been previously published. ${ }^{232728}$ Histological verification of diagnosis has been obtained in seven affected members of Family 1 and six patients in Family 2. 


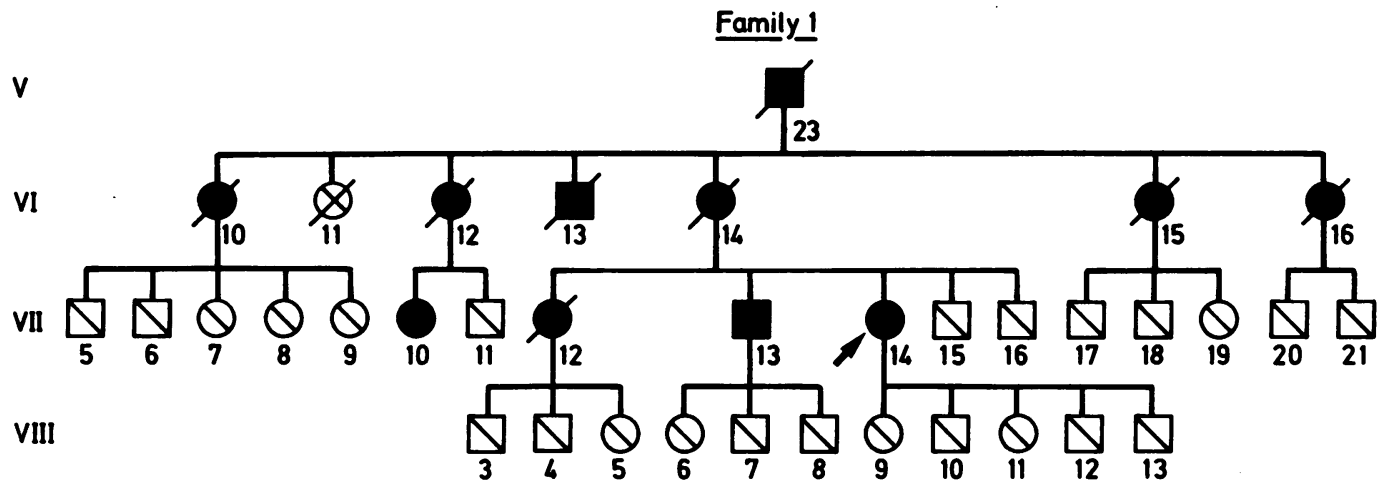

Family 2
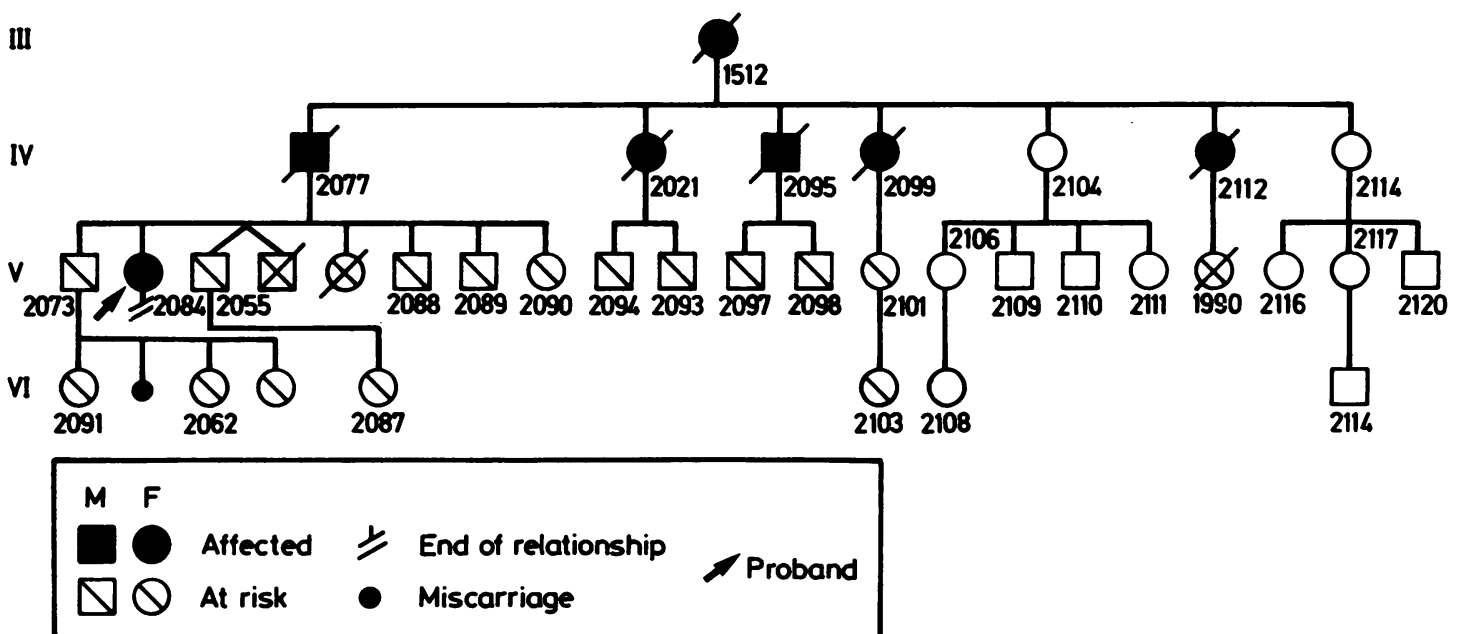

Fig 1 Small segments of the complete pedigrees illustrating the pattern of Alzheimer's disease transmission in Families 1 and 2. The index cases studied by PET are indicated. The at-risk subjects studied (not marked) are direct descendants of affected family members. Complete pedigrees have been previously published as indicated in the text.

Case 1 (Family 1, Pedigree No VII-14) This 55 year old right-handed, married Caucasian female, manifested gradual decline in concentration and memory approximately three years before admission. The insidious progression of intellectual impairment made it increasingly difficult to continue work as a nurses' aide. Her family indicated that the symptoms had progressed and she became unable to manage money and complete household chores. Neurological examination confirmed a striking impairment of recent memory with preservation of remote memory. She also exhibited speech perseveration, dyscalculia, difficulty with problem solving, and reduced digit span. Her insight was poor. Motor apraxia, hyperactive deep tendon reflexes and a snout reflex were present. A mild to moderate degree of dementia was indicated by a Blessed Dementia scale rating of 8 (maximum score $=28$ ). EEG showed diffuse slowing with low voltage background activity. CT and MRI scans of the head were considered normal.
Case 2 (Family 2, Pedigree No V-2084) Two years ago this 40 year old right handed, single Caucasian female developed gradual loss of short term memory, word finding difficulty, and receptive aphasia. She recognised her symptoms as early signs of Alzheimer's disease and discontinued work as an emergency room nurse. Activities of daily living are presently performed without difficulty. Neurological examination was remarkable for profound loss of short term memory, disorientation to place, mild fluent dysphasia, dyscalculia, poor problem solving ability, and reduced digit span. The Blessed Dementia Scale rating was 10 , confirming a moderate dementia. EEG revealed low voltage irregular disorganised background with some diffuse paroxysmal activity. CT scan of the head showed minimal prominence of sulci with normal ventricles.

\section{PET Scanning}

All subjects were kept fasting for 5 hours prior to PET scan- 
ning. An indwelling needle was inserted into a vein in an upper extremity for withdrawing blood samples. "Arterialisation" of the venous blood was accomplished by heating the hand to $44^{\circ} \mathrm{C}$ with a heating pad. Prior to and during the initial 30 minutes following the rapid injection of 5 millicuries of FDG, patients were kept lying still in a quiet, isolated room while wearing eye patches and ear plugs. Following intravenous isotope administration, samples for measurement of FDG and glucose concentrations were taken from the opposite arm every 30 seconds for the first 5 minutes, with the frequency decreasing to 15 minutes per sample toward the end of the scanning period. Three 10 minute scans were performed, each yielding seven slices, giving a total of 21 image planes, parallel to the canthomeatal (CM) plane, at $4 \mathrm{~mm}$ increments, ranging from $\mathrm{CM}+$ $20 \mathrm{~mm}$ to the vertex. Cross-sectional images were reconstructed and evaluated using the Neuro-PET computer. The scanner has a spatial resolution of 6-7 mm full width at half maximum (FWHM) and a sensitivity of $70,000 \mathrm{c} / \mathrm{s}(\mu \mathrm{Ci} / \mathrm{ml})$ for a true slice with medium energy threshold $(375 \mathrm{keV}){ }^{29} \mathrm{~A}$ calculated attenuation correction is incorporated in the image reconstruction programme, based on the actual edge of the scalp which is visible on the images, and including an estimated $5 \mathrm{~mm}$ thick underlying skull.

\section{Data Analysis}

The cerebral cortex and basal ganglia for all subjects were mapped by the same examiner using a "region of interest" (ROI) programme. At specified heights above the CM plane, contiguous, non-overlapping ROIs were positioned within a given PET slice to locate peak metabolic rates. For the cerebral cortex, a $10 \mathrm{~mm} \times 10 \mathrm{~mm}$ elliptical ROI was used; a $7 \mathrm{~mm} \times 7 \mathrm{~mm}$ ellipse was used for the basal ganglia. Peak and mean cerebral metabolic rates were calculated with rate constants determined for normal subjects using a modified version of the Sokoloff operations equation. ${ }^{30}$ The lumped constant was taken as 0.420 and the four transfer constants for grey matter as: $\mathrm{K}_{1}{ }^{*}=0.102 \mathrm{~min}^{-1}, \mathrm{~K}_{2}{ }^{*}=0.130 \mathrm{~min}^{-1}$, $\mathrm{K}_{3}{ }^{*}=0.062 \mathrm{~min}^{-1}, \mathrm{~K}_{4}{ }^{*}=0.0068 \mathrm{~min}^{-1}$; and those for white matter as: $\mathrm{K}_{1}{ }^{*}=0.054 \mathrm{~min}^{-1}, \mathrm{~K}_{2}{ }^{*}=0.109 \mathrm{~min}^{-1}$, $\mathrm{K}_{3}{ }^{*}=0.045 \mathrm{~min}^{-1}, \mathrm{~K}_{4}{ }^{*}=0.0058 \mathrm{~min}^{-1} .{ }^{5}$ While a recent study, ${ }^{31}$ and our own independent measurements, have indicated that the true lumped constant is about 0.53 , we used the lower value for better comparison with the existing literature on Alzheimer's disease subjects, which is almost invariably based on the original value reported by Phelps $e t$ $a l^{5}$ A brain atlas was used for identifying specific anatomical regions. ${ }^{32}$

A mean metabolic rate for each region was calculated if two or more ROIs were located within a specific anatomical region. This average was used as the metabolic rate for each identified area in each subject. The following areas were identified in each hemisphere for every subject: frontal lobe, pre-central gyrus, post-central gyrus, supramarginal gyrus, temporal lobe, parietal lobe, occipital lobe, amygdala, caudate, putamen, hippocampus, and parahippocampal gyrus.

Data for the two affected subjects were grouped and compared with the four control subjects by analysis of variance with appropriate follow-up tests. In order to determine which regional differences were reduced out of proportion to any generalised decrease in cerebral glucose metabolic rate (CMRGlu), all values were normalised to the respective average CMRGlu for each hemisphere. These normalised values were compared among the groups by analysis of variance. The at-risk subjects were compared individually with the control group.

\section{Results}

Visual analysis of the scans obtained in the Alzheimer's disease patients revealed a substantial reduction of glucose metabolism in the parietal and temporal lobes. This wedge-shaped decrease in metabolism appears to be bilaterally symmetrical (fig 2). The global pattern of glucose metabolism appeared normal in the two at-risk family members.

Calculation of the regional CMRGlu in the Alzheimer's disease patients revealed that all areas except the caudate showed a significant bilateral reduction compared to the controls. This is reflected in the average for both left and right hemispheres which are respectively reduced by $36.8 \%$ and $34.2 \%$ (fig 3). The normalised values for CMRGlu in the supramarginal gyrus and temporal lobe were bilaterally decreased in the Alzheimer's disease patients (fig 4). Neither hemisphere was predominantly affected in the Alzheimer's disease patients.

Although the regional values for CMRGlu were generally lower than normal in one at-risk subject, the differences were not statistically significant. However, the normalised CMRGlu for the left supramarginal gyrus in this same subject is significantly less than the control group (fig 4).

\section{Discussion}

The results of this study demonstrate a bilateral generalised reduction in the rate of cerebral glucose metabolism which is most severe in the supramarginal gyri and temporal lobes in patients with dominantly inherited Alzheimer's disease. Although the values in the Alzheimer's disease patients were lower in the left hemisphere, the asymmetry was not significant. It is premature to draw conclusions from the one significant reduction in the normalised CMRGlu in the left supramarginal gyrus of the second at-risk patient. PET has been used to measure local cerebral blood flow, oxygen consumption, and glucose metabolic rate in patients with dementia including Alzheimer's disease (for review, see Refs 33, 34). Using a steady-state ${ }^{15} \mathrm{O}$ technique coupled with PET scanning, Frackowiak et al first demonstrated a temporo-parietal decline in metabolism in milder patients with degenerative dementia. ${ }^{35} \mathrm{~A}$ reduction in the frontal regions occurred later in the course of the disease. They also correlated the changes in metabolism with severity of dementia. Two of their patients had histological evidence of degenerative dementia. There is only one other necropsy proven Alzheimer's 

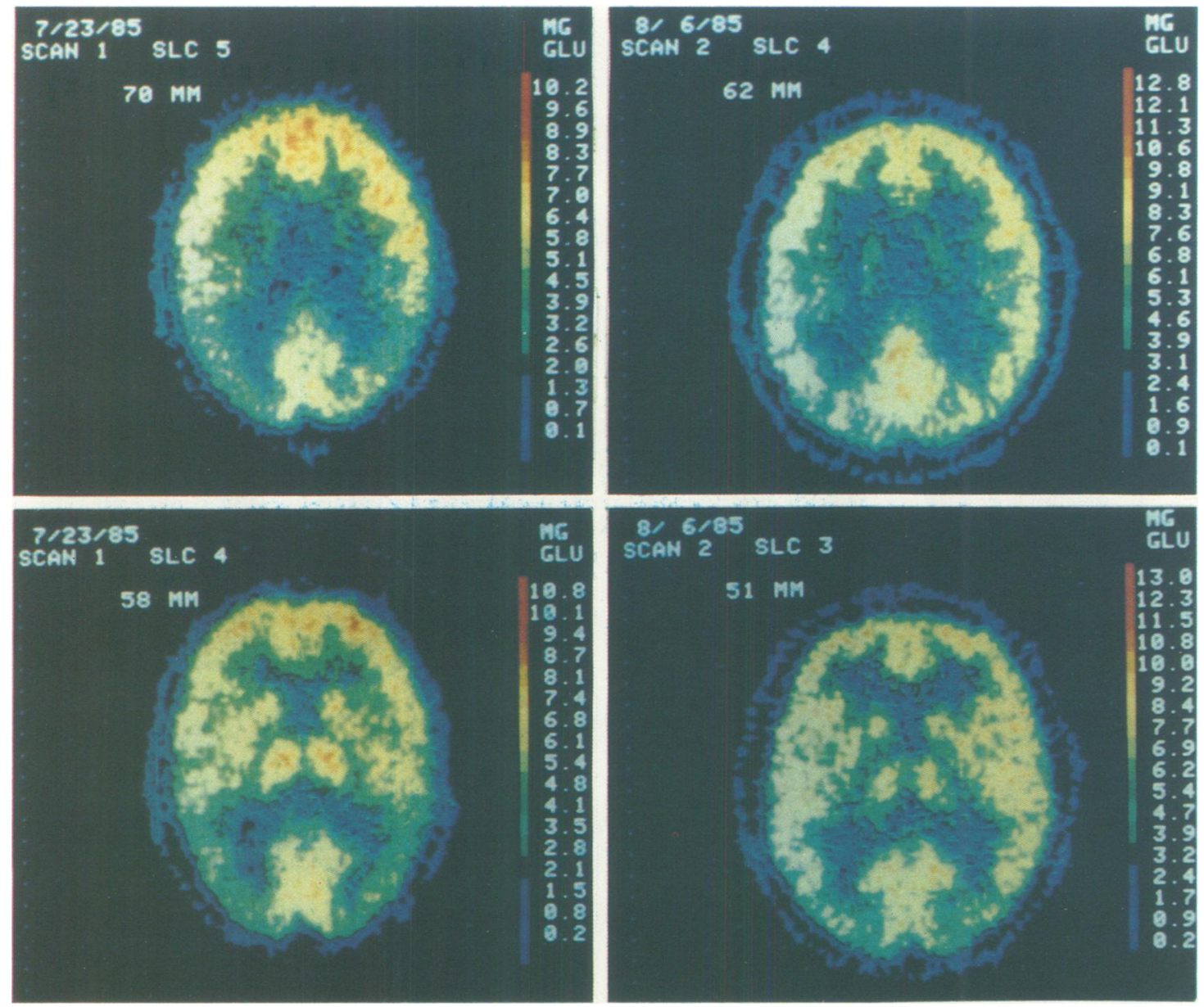

Fig 2 PET scan images on one Alzheimer's disease patient (left) and an at-risk subject (right). The temporo-parietal reduction in CMRGlu is evident in the Alzheimer's disease patient compared to the normal scan of the at-risk subject.

disease case studied by PET but this patient was the most severely demented patient in that study and had a global decrease in metabolism. ${ }^{19}$ There is generally agreement among previous studies that CMRGlu in temporo-parietal brain regions is reduced out of proportion to other areas. This pattern of hypometabolism parallels the magnitude and anatomical distribution of neuropathological alterations found in detailed, regional examinations of Alzheimer's disease brains. ${ }^{36}$ Our findings confirm and provide additional validation of results obtained by other investigators in early presumed Alzheimer's disease cases. The overall reductions of $36.8 \%$ and $34.2 \%$ in CMRGlu are consistent with the decreases of $10-49 \%$ observed by others. 10111419

Familial Alzheimer's disease cases in general do not provide a homogeneous population with improved diagnostic accuracy. There is only one previous report of the PET findings in a patient with familial Alzheimer's disease. ${ }^{17}$ The most important differences between the case reported by Cutler et al and those of the present series are variable clinical expression of Alzheimer's disease within that family and more importantly, lack of a well-defined inheritance pattern in the Cutler et al case. In the present study the pedigrees are sufficiently large to allow identification of autosomal dominant transmission. The frequent occurrence of Alzheimer's disease in the general population substantially reduces the value of studying small familial clusters with heterogeneous clinical expression.

In addition to the problem of diagnostic accuracy 


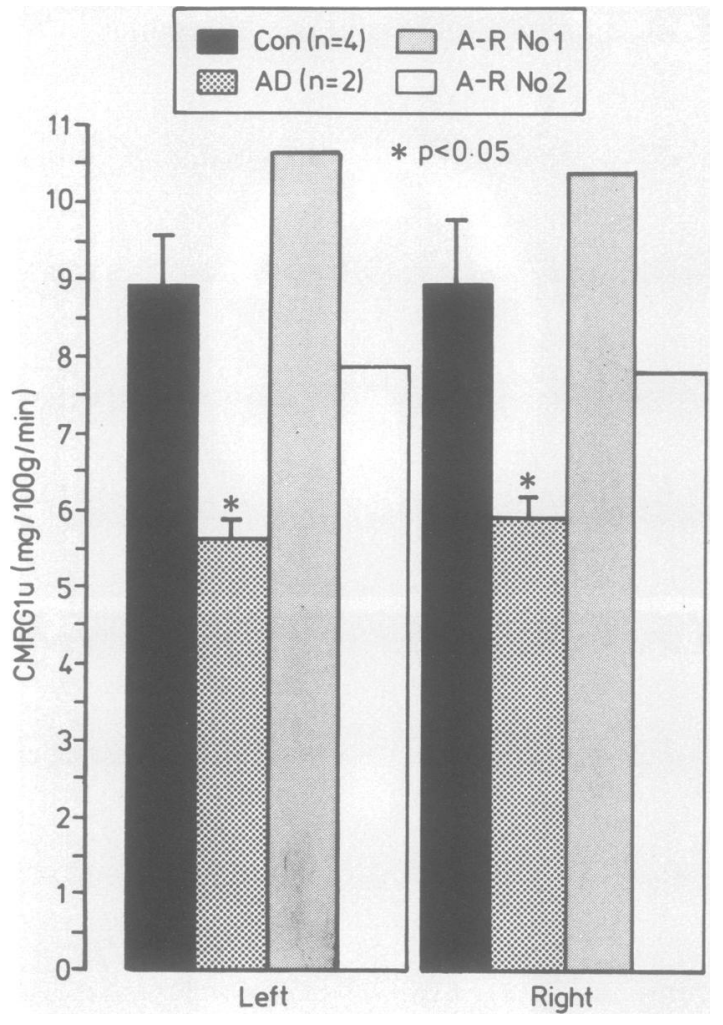

Average value for hemisphere

Fig 3 Average CMRGlu values for each hemisphere.

in Alzheimer's disease, there are technical limitations in analysing PET scans. We have used small regions of interest to minimise partial volume effects. Our patients did not have significant atrophy which would hamper comparison with the control group. We adjusted the region of interest placement within each structure to provide the maximum value, assuming that this position gives the smallest partial volume effect with a high resolution scanner. Although the net result of this method is an increase in the absolute CMRGlu values, the same approach has been applied to both controls and patients enabling a standardised statistical comparison. Our control values are similar, however, to published data obtained using the NeuroPET. ${ }^{37}$

The importance of our findings lies in the improved diagnostic accuracy inferred from a dominant mode of inheritance and multiple histological confirmations within a single pedigree. In the absence of a specific Alzheimer's disease genetic marker or brain biopsy, there are no other means by which a diagnosis can be more clearly established in the living patient, particularly in the early stages. The demonstration of similar

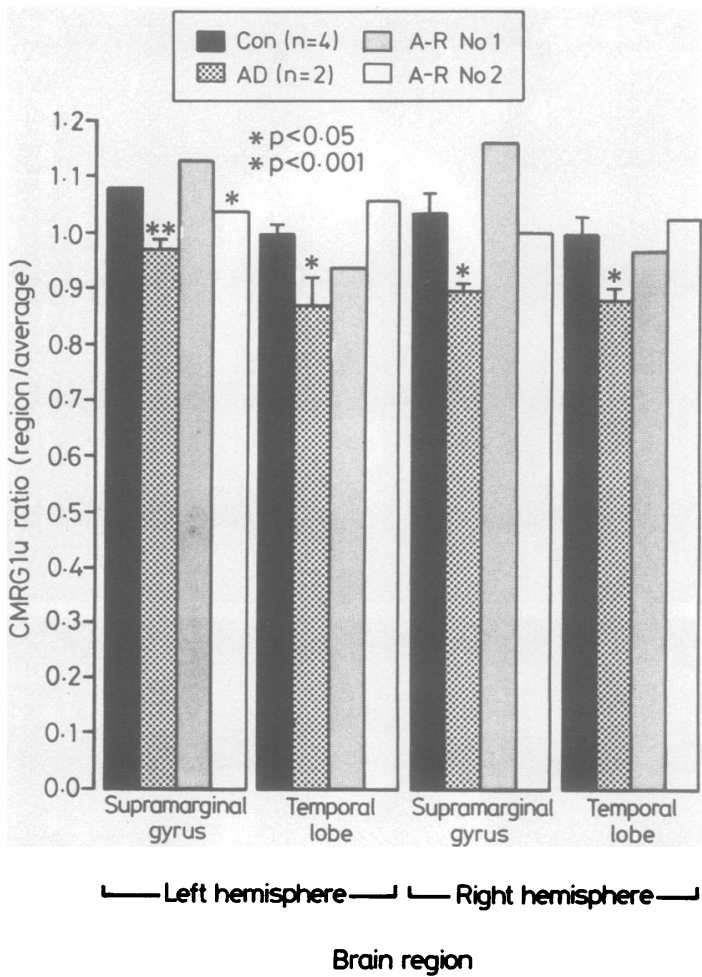

Fig 4 Normalised CMRGlu values for the supramarginal gyrus and temporal lobe in each hemisphere.

PET findings in dominantly inherited and sporadic Alzheimer's disease cases forms the basis for a longitudinal investigation of the at-risk members of these families. These families are an invaluable resource that permits application of a valid strategy for studying an illness with otherwise uncertain ante-mortem diagnosis and for which no adequate animal model exists.

We are grateful to Ms Justine $\mathbf{R}$ Ballard who assisted in the preparation of this manuscript and the nurses of Ward 5 East, NIH Clinical Center, who cared for the patients during this study. We appreciate the comments and suggestions of Dr Rodney Brooks who reviewed this manuscript.

\section{References}

1 Garcia C, Reding MJ, Blass JP. Overdiagnosis of dementia. J Am Geriatr Soc 1981;19:407-10.

2 Nee LE, Polinsky RJ, Eldridge R, Weingartner $H$, Smallberg S, Ebert M. A family with histologically confirmed Alzheimer's disease. Arch Neurol 1983; 40:203-8. 
3 Feldman RG, Chandler KA, Levy LL, Glaser GH. Familial Alzheimer's disease. Neurology 1963;13: 811-24.

4 Foncin JF, Salmon D, Supino-Viterbo V, et al. Demence presenile d'Alzheimer transmise dans une famille etendue. Rev Neurol (Paris) 1985;141:194-202.

5 Phelps ME, Huang SC, Hoffman EJ, Selin C, Sokoloff L, Kuhl DE. Tomographic measurement of local cerebral glucose metabolic rate in humans with (F-18) 2-fluoro-2-deoxy-d-glucose, validation of method. Ann Neurol 1979;6:371-88.

6 Reivich M, Kuhl D, Wolf A, et al. The $\left({ }^{18} \mathrm{~F}\right)$ fluorodeoxyglucose method for the measurement of local cerebral glucose utilization in man. Circ Res 1979;44:127-37.

7 Hoyer S. Cerebral blood flow, electroencepholography and behavior. In: Platt D, ed. Geriatrics. 1. Cardiology and vascular system, central nervous system. Berlin: Springer-Verlag, 1982:201-60.

8 Benson DF, Kuhl DE, Hawkins RA, Phelps ME, Cummings JL, Tsai SY. The fluorodeoxyglucose $18 \mathrm{~F}$ scan in Alzheimer's disease and multi-infarct dementia. Arch Neurol 1983;40:711-4.

9 de Leon MJ, Ferris SH, George AE, et al. Positron emission tomographic studies of aging and Alzheimer disease. AJNR 1983;4:568-71.

10 Foster NL, Chase TN, Mansi L, et al. Cortical abnormalities in Alzheimer's disease. Ann Neurol 1984; 16:649-54.

11 Chase TN, Foster NL, Fedio P, Brooks R, Mansi L, Di Chiro G. Regional cortical dysfunction in Alzheimer's disease as determined by positron emission tomography. Ann Neurol 1984;15(suppl):S170-4.

12 Kuhl DE, Metter EJ, Riege WH, Hawkins RA. Determination of cerebral glucose utilization in dementia using positron emission tomography. Dan Med Bull 1985(suppl 1):51-5.

13 Friedland RP, Budinger TF, Ganz E, et al. Regional cerebral metabolic alterations in dementia of the Alzheimer type: positron emission tomography with $\left({ }^{18} \mathrm{~F}\right)$ fluorodeoxyglucose. J Comput Assist Tomogr 1983;7:590-8.

14 de Leon MJ, George AE, Ferris SH, et al. Regional correlation of PET and CT in senile dementia of the Alzheimer type. AJNR 1983;4:553-6.

15 Foster NL, Chase TN, Fedio P, Patronas NJ, Brooks RA, Di Chiro G. Alzheimer's disease: focal cortical changes shown by positron emission tomography. Neurology 1983;33:961-5.

16 de Leon MJ, Ferris SH, George AE, et al. Computed tomography and positron emission transaxial tomography evaluations of normal aging and Alzheimer's disease. J Cereb Blood Flow Metab 1983;3:391-4.

17 Cutler NR, Haxby JV, Duara R, et al. Brain metabolism as measured with positron emission tomography: serial assessment in a patient with familial Alzheimer's disease. Neurology 1985;35:1556-61.

18 Cutler NR, Haxby JV, Duara R, et al. Clinical history, brain metabolism, and neuropsychological function in Alzheimer's disease. Ann Neurol 1985;18:298-309.

19 Friedland RP, Budinger RF, Koss E, Ober BA. Alzheimer's disease: anterior-posterior and lateral hemispheric alterations in cortical glucose utilization. Neurosci Lett 1985;53:235-40.
20 Koss E, Friedland RP, Ober BA, Jagust WJ. Differences in lateral hemispheric asymmetries of glucose utilization between early- and late-onset Alzheimer-type dementia. Am J Psychiatry 1985;142:638-40.

21 Haxby JV, Duara R, Grady CL, Cutler NR, Rapoport SI. Relations between neuropsychological and cerebral metabolic asymmetries in early Alzheimer's disease. J Cereb Blood Flow Metabol 1985;5:193-200.

22 Foster NL, Chase TN, Fedio P, Patronas NJ, Brooks RA, DiChiro G. Alzheimer's disease: focal cortical changes shown by positron emission tomography. Neurology 1983;33:961-5.

23 Grimes AM, Grady LC, Foster NL, Sunderland T, Patronas NJ. Central auditory function in Alzheimer's disease. Neurology 1985;35:352-8.

24 Foster NL, Chase TN, Patronas NJ, Gillespie MM, Fedio P. Cerebral mapping of apraxia in Alzheimer's disease by positron emission tomography. Ann Neurol 1986;19:139-43.

25 Ferris SH, de Leon MJ, Wolf AP, et al. Positron emission tomography in the study of aging and senile dementia. Neurobiol Aging 1980;1:127-31.

26 Blessed G, Tomlinson BE, Roth M. The association between quantitative measures of dementia and of senile change in the cerebral grey matter of elderly subjects. Br J Psychiatry 1968;114:797-811.

27 Krigman MR, Feldman RG, Bensch K. Alzheimer's presenile dementia. A histochemical and electron microscopic study. Lab Invest 1965;14:381-96.

28 Foncin JF, Supino-Viterbo V. Maladie d'Alzheimer familiale: histopathologie ultrastructurale, etude genealogique. Ecerpta Medica International Congress Series n296, 1973.

29 Sank VJ, Brooks RA, Friauf WS, Leighton SB, Cascio HE, DiChiro G. Performance evaluation and calibration of the Neuro-PET scanner. IEEE Trans Nuclear Science 1983;NS-30:636-9.

30 Brooks RA. Alternative formula for glucose utilization using labeled deoxyglucose. J Nucl Med 1982;23: 528-39.

31 Reivich M, Alavi A, Wolf AP, et al. Glucose metabolic rate kinetic model parameter determination in man: the lumped constants and rate constants for $\left({ }^{18} \mathrm{~F}\right)$ fluorodeoxyglucose and $\left({ }^{11} \mathrm{C}\right)$ deoxyglucose. $J$ Cereb Blood Flow Metab 1985;5:179-92.

32 Aquilonius S, Eckernas S, eds. A Colour Atlas of the Human Brain. New York: Raven Press, 1980.

33 Mazziotta JC. Human cerebral metabolism: studies in normal subjects and patients with dementia and amnesia. Ann NY Acad Sci 1985;444:269-86.

34 Phelps ME, Mazziotta JC. Positron emission tomography: human brain function and biochemistry. Science 1985;228:799-809.

35 Frackowiak RSJ, Pozzilli C, Legg NJ, et al. Regional cerebral oxygen supply and utilization in dementia. Brain 1981;104:753-78.

36 Friedland RP, Brun A, Budinger TF. Pathological and positron emission tomographic correlations in Alzheimer's disease. Lancet 1985;1:228.

37 DiChiro G, Oldfield E, Bairamian D, et al. Metabolic imaging of the brain stem and spinal cord: studies with positron emission tomography using ${ }^{18} \mathrm{~F}$-2-deoxyglucose in normal and pathological cases. J Comput Assist Tomogr 1983;7:937-45. 